\title{
Ethnomedicobotany: People Health through Wild Plant Resources
}

\author{
Gopal Dixit* \\ Centre of Research in Ethnobotany, Upadhi PG College, MJP Rohilkhand University, India \\ *Corresponding author: Gopal Dixit, Centre of Research in Ethnobotany, Upadhi PG College, MJP Rohilkhand University, India
}

\section{Short communication}

Ethnomedicine is an area of research that deals with medicines derived from plants, animals and minerals etc. and used in the treatment of different human and veterinary ailments. Ethnomedicines includes indigenous beliefs, concepts, knowledge and practices among the ethnic groups, folk people and rural people for preventing, minimizing or curing various diseases. For this purpose, human groups around the world utilized the biological and cultural resources in their own way to develop resistance to combat different diseases, illness and health hazards arising from different pathogens and agents. The ethnic people and tribal races throughout the world have developed their own cultures, customs, cults, rituals, taboos, totems, myths, song, edible and medicinal practices. Wild and cultivated plants play a very crucial and vital role in their cultures through generations long experiences and experiments. The accomplishment and achievements of forest dwelling ethnic groups in understanding plants and properties of their roots, stems, leaves, flowers, fruits, seeds and underground parts is chiefly due to long and unconditional relationship with the vegetation and their survival on them. Although, their traditional knowledge is based on repeated experimentation through trial and error methods but still needed careful considerations. It provides an opportunity to modern civilization to take an advantage of their vast knowledge of natural resources for scientific reviews and acceptance. In many ethnic communities, health status, disease causes, and treatment practices are chiefly based upon herbal resources. These unwritten medical practices collectively constitute 'Ethnomedicine'. This unwritten indigenous knowledge of ethnic people has been passed by the words of mouth from generation to generation. In most of ethnic communities there are specialist medicine men or sometimes women. These specialists are having vast knowledge of plants growing to nearby them and usually acquires faith and beliefs of their communities.
In most of tribal communities, two systems of medical practice have been observed. In the first system, psychoactive plants, as considered to be scared, are used to communicate with visions and hallucinations. On the other hand, the second system of medical practice is mainly based on medicinal plants. This knowledge is amassed by experimentation over large number of population and passed on orally from generation to generation Schultes and Reis [1].

Herbal medicines are believed to be the oldest form of health care known to human beings. Herbs had been used by all sections and cultures of the society throughout the world. It was an initial stage of modern civilization of present time. Use of medicinal plants have been developed through observations on wild animals and by trial and error methods. As the time passes each tribe has added new medicinal plants growing in their locality.

Traditional medicine can be broadly classified into the following basic systems as

a) Traditional Chinese Medicines.

b) Traditional Japanese Medicine, Kampo.

c) Tibetan Medicine

d) Mongolian Medicine.

e) Dai Medicine of South Yunnan Province of China.

f) Ayurveda.

g) Siddha associated with Tamils of India.

h) Unani, the Islamic system of Medicine.

i) Uigur Medicine practiced in North West China.

j) Homoeopathy developed by Samuel Hahnemann. 


\section{k) Western Medicine, referred as Allopathic Medicine}

Ancient cultures throughout the world have vast amounts of knowledge pertaining to the use of flora of their residing localities. This indigenous knowledge is of great practical value and appears toward extinction in most of localities due to rapid acculturation and civilization of tribal people. The loss of this ethnic knowledge should be checked at any cost, hence documentation, prioritization and validation of this unwritten knowledge through Intellectual Property Rights is the chief motive of ethno botany in general and ethno medico botany in particular Dixit [2].

\section{References}

1. Schultes RE, Reis S von (1995) Ethnobotany: Evolution of a discipline. Champman and Hall, London UK.

2. Dixit Gopal (2018) Ethnobotany: Prioritization and Validation of New Prospects. J Ag Sc Bot 2(4): 1-2.

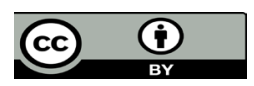

This work is licensed under Creative Commons Attribution 4.0 License

Submission Link: Submit Article

DOI: $10.32474 /$ DDIPIJ.2019.02.000148

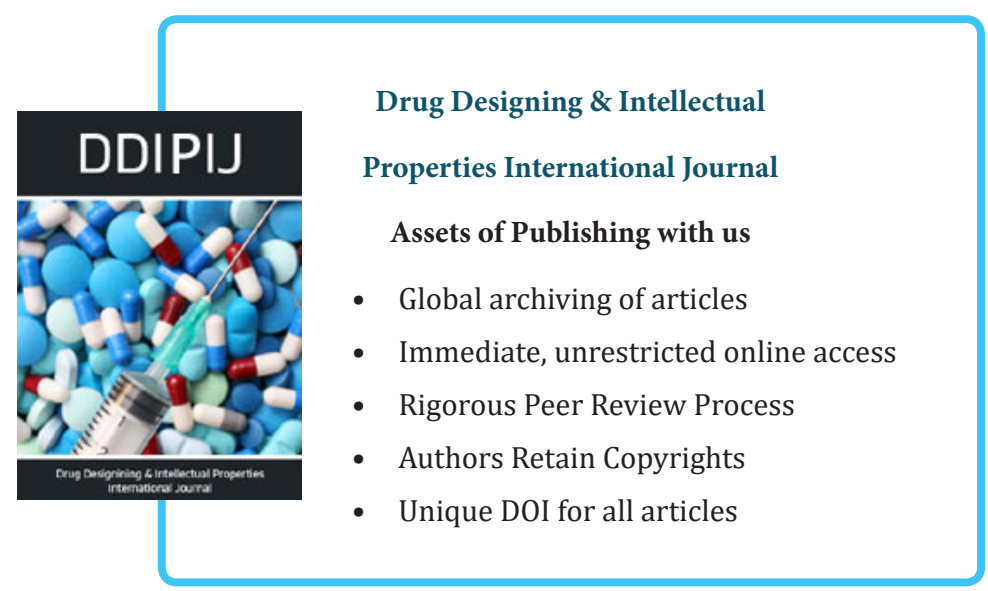

